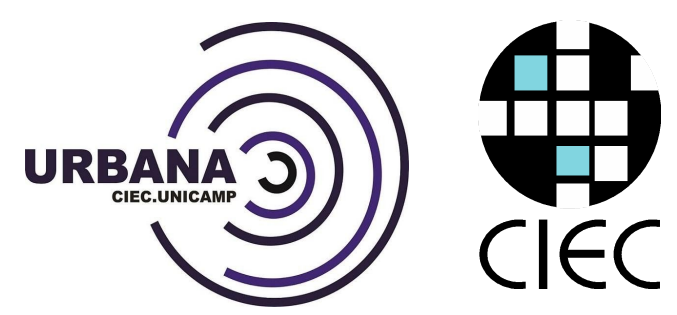

URBANA: Revista Eletrônica do Centro Interdisciplinar de Estudos sobre a Cidade

Ricardo Luis Silva

ricardo.Isilva@sp.senac.br | Centro Universitario Senac

\title{
Cartografia como narrativa
}

Experiências artísticas de Guillermo Kuitca e Jorge Macchi como procedimento de leituras urbanas

\section{Cartografia como narrativa}

Experiencias artísticas de Guillermo Kuitca y Jorge Macchi como procedimiento de lectura urbana

\section{Cartography as narrative}

Artistic experiences of Guillermo Kuitca and Jorge Macchi as urban reading procedure

\section{Resumo | Abstract | Resumen}

\section{Introdução}

Arquitetura e Arte têm, vez ou outra na história da civilização moderna, alargados seus discursos, contaminando-se mutuamente', e desconstruído seus limites disciplinares que demarcam e especificam cada uma delas. Momentos de limites claros e

\footnotetext{
1 A arte de vanguarda dos anos 1910-1930, a exemplo do Cubismo, ou mesmo o Neoplasticismo anos mais tarde contaminaram os discursos de Le Corbusier e seus contemporâneos da nascente arquitetura racional-funcionalista. Ou então as explorações arquitetônicas e urbanas empreendidas pelos grupos de arquitetos pós-CIAM nos anos 1950 e os coletivos radicais do Archigram, Superstudio, Archizoom, Antfarm etc, nos anos 1960, que contaminaram os discursos artísticos com considerações espaciais e urbanas.
} 
protecionistas, momentos de limites difusos e rarefeitos, e até momentos de ausência e transgressão total a qualquer nuance de limite.

Independente da validade destes limites, das possibilidades e impossibilidades desse trânsito sobre essa fronteira tão tênue e subjetiva, a Arquitetura e a Arte sempre estiveram próximas e lindeiras nas construções culturais, sociais, estéticas, éticas e, especial para este texto, urbanas e cotidianas. E mesmo não considerando qualquer juízo ou valor sobre esse limite, é inegável que esta vizinhança disciplinar fornece o empréstimo de questões conceituais, críticas, formais e reflexivas uma a outra, em ambos os sentidos. A Arquitetura se aproveita de questões pertinentes à Arte para benefício e reforço de discursos, assim como o caminho contrário também se estabelece. Isso se evidencia - e acirra o debate da fragilidade daquela fronteira disciplinar - quando a Arte, nos idos dos anos 1960, abandona os espaços institucionais dos museus, galerias e ateliers e parte em direção à Cidade, ao espaço público, ao cotidiano urbano.

Essa sensibilização de esvanecimento das fronteiras entre as duas disciplinas, quase como uma duplicação espectral diante de um espelho, abre-nos a possibilidade de observarmos através dele, ou para mudar a analogia, olharmos por sobre o muro, talvez até já inexistente, que separa Arquitetura da Arte, principalmente a parte dessa última voltada aos espaços e discussões urbanas. Artistas vêm tratando, intervindo e refletindo sobre o espaço da Cidade, a partir de suas práticas artísticas e descompromissados com diversos "entraves" disciplinares inerentes e caracterizadores da Arquitetura. E isso nos provoca: O que tais artistas estão fazendo com a Cidade, que questões estão levantando, como as estão levantando? Que reflexões, críticas e especulações fazem esses "estrangeiros", mas vizinhos, perante esse objeto que sempre foi, ou esperava-se que fosse, pelo menos pelos arquitetos mais protetores da pureza da disciplina, de exclusividade da Arquitetura? 
Que se estabeleça aqui uma alteridade, não apenas urbana, mas também disciplinar. Conviver, co-existir com a Arte e os artistas na Cidade pode apresentar caminhos válidos para a investigação do viver urbano tão caro aos arquitetos. Olhemos por sobre o muro, pois

Foram os artistas que me ensinaram a observar com seriedade os objetos que não pareciam merecedores de interesse, ou que eram de interesse somente dos especialistas. Os artistas modernos demonstraram que meros fragmentos colhidos do cotidiano de um determinado período podem revelar seus hábitos e sentimentos; que devemos ter a coragem de tomar pequenas coisas e alçá-las a grandes dimensões. (GIEDION, 2004, p. 31) $)^{2}$

Além disso, a Arte apresenta uma característica peculiar e incontestável, que acrescentará uma carga fundamental nesse observar por sobre o muro. A Arte é, sem sombra de dúvida, pelo menos aos olhos do autor desta hipótese, o campo primordial, o objeto inicial das reflexões, a ação máxima do ser humano, quando pretendemos estabelecer a proposta da inutilidade. A Arte é inútil por excelência, ou como seca e taxativamente nos apresenta Oscar Wilde, no prefácio do seu livro O Retrato de Dorian Gray, “Toda arte é perfeitamente inútil." (2009, p. 03); ou mesmo a sensível provocação de Théophile Gautier, ao apresentar e justificar sua admiração pelo amigo Charles Baudelaire,

Só é realmente belo o que não serve para nada; tudo que é útil, é feio, pois é a expressão de uma necessidade e as do homem são ignóbeis e nojentas, como sua natureza pobre e enferma. O lugar mais útil de uma casa são as latrinas. (GAUTIER, 2001, p. 23)

São nessas duas capacidades da Arte, a inutilidade primordial e o experimentar urbano, que se pretende debruçar. É na essência inútil da Arte que se enxerga possibilidades para construirmos

\footnotetext{
2 Siegfrid Giedion, arquiteto e crítico chave nas discussões com Le Corbusier acerca do movimento Funcionalista nos CIAMs, foi aluno de Heinrich Wölfflin (1864-1945), historiador e crítico de arte suíço, professor também de Walter Benjamin.
} 
pontes, conexões, vislumbres aproximativos, entre a Cidade e o Homem, dando evidências de uma concreta e efetiva apropriação do espaço urbano. Mas não vale estabelecer um labirinto conceitual aprofundando e confrontando tantos discursos e críticas à Arte que nos envolvem atualmente, coisa que demandaria uma outra infinidade de estudos. A intenção é mais humilde e observadora, é ser um colecionador, produzir uma aproximação catalográfica.

Enfim, é potencial ao discurso proposto, olharmos para além da disciplina urbana, além da Arquitetura, além do Urbanismo. Observar a Arte, ou pelo menos mínimos fragmentos de ações artísticas. Reconhecer em outras mãos, não especialistas, mas inúteis, agenciamentos de ações de investigação e apropriação honestas, subjetivas, conscientes, em busca de um esclarecimento e autonomização do sujeito perante o espaço urbano contemporâneo. Vislumbrar em algumas ações artísticas recentes caminhos factíveis para uma incorporação do Trapeiro. Perceber, dentro do nosso tempo, nossa contemporaneidade, artistas e obras de arte que representem e efetivem a alegoria do Trapeiro do século XX/XXI.

Com esse desejo científico seguir os passos sugeridos pela ação especulativa de Charles Baudelaire que, em 1863, no texto 0 Pintor da vida Moderna, observou e constituiu um olhar crítico sobre os desenhos de Constantin Guys, o aproximando da sua alegoria pretendida naquele momento: a figura do Flâneur.

Como sabemos Baudelaire observa, inventaria e disseca os desenhos e esboços do Sr. G., produzidos expeditamente nas ruas das cidades, resultantes das buscas do "artista-repórter" por assuntos elegíveis a matérias dos jornais enquanto circulava pelo espaço urbano e seus movimentos cotidianos. Nesse ato de inventariar, Baudelaire reconhece e "descobre" características de um olhar curioso que lhe parece único, original, moderno. O poeta-crítico vê no artista-repórter a personificação da figura do Flâneur.

Assim como Baudelaire (2010) fez com o "observador apaixonado" (p. 30), o “homem-criança" (p. 28), o "eterno 
convalescente" (p. 28), o "solitário dotado de imaginação ativa" (p. 35), faremos também com o Trapeiro. O que vem a seguir são artistas-colecionadores. Colecionadores de Cidades, de fragmentos resignificados como discurso de vida urbana cotidiana. Eles serão reunidos, apresentados e algumas de suas obras inventariadas.

Tais inventários não se destinam a construção de um guia de recomendações, posturas ou ações prontas a serem reproduzidas ou transformadas em atitudes e métodos de apropriação da cidade. São construções de processos de leitura e olhar crítico sobre nossas relações com os espaços urbanos.

\section{Mapas, leitura no tempo}

Os artistas selecionados aqui usam o mapa como instrumento, motivo, suporte, produto de várias de suas obras. A arte, no século $X X$ e, com bastante intensidade, nesse início de século XXI, tem se apropriado em diversas ocasiões de mapas e cartas, utilizando-os em alguma etapa da criação artística. Mas também os elementos cartográficos sempre sofreram contaminações das artes visuais, seja no estilo, no referencial estético, seja na construção de linguagem simbólica. Mapas são, fundamentalmente, representações de um mundo observado e desenhado.

Mais ainda, mapas por definição são utilitários, carregam promessas implícitas de realidade e rotas para dentro e fora do desconhecido. Solicitamos fidelidade aos mapas, acreditamos naquilo que eles nos mostram. Confiamos aos mapas a capacidade de revelação, duplicação, informação do território sobre o qual são baseados. Os mapas são, ou pretendem ser, portadores da verdade.

Portar a verdade implica-lhes outra característica: o poder. Mapas são poderosos justamente porque confiamos no que eles nos apresentam. Além disso, como lembram as pesquisadoras Maria Perrone Passos e Teresa Emídio (PASSOS, 2009), os mapas tanto indicam, revelam, explicitam, corroboram os poderes espaciais, políticos e sociais da cidade, da sua época e do seu produtor (o 
cartógrafo), quanto constituem e dão poder aos seus produtores, num primeiro momento, e aos seus detentores num segundo momento. Em outras palavras, os mapas são verdadeiros, por isso têm poder, e também são instrumentos de controle e dominação, e por isso dão poder, são poderosos e empoderadores; “o poder dos mapas e os mapas do poder". Poderosos e, por isso, perigosos.

Perigosos porque são sedutores e inebriantes, envolventes. Visualizar um mapa é vislumbrar o território além do alcance da vista, é simular um olhar superior, divino. Ter um mapa do território nas mãos é antecipar a posse, o domínio daquele território representado. Produzir um mapa é ter à disposição o gesto de repetir o mundo, duplicá-lo em miniatura.

Jorge Luis Borges, escritor e poeta argentino, publicou certa vez um minúsculo conto intitulado "Del rigor en la ciencia" ${ }^{3}$ (1946/1960), onde nos coloca perante o risco que corremos naquela "sedução cartográfica"

(...) Naquele império, a arte da cartografia alcançou tal perfeição que o mapa de uma única Província ocupava toda uma cidade, e o mapa do Império, toda uma Província. Com o tempo, esses mapas desmesurados não foram satisfatórios e os Colégios de Cartógrafos levantaram um mapa do Império, que tinha o tamanho do Império e coincidia pontualmente com ele. Menos afeitas ao Estudo da Cartografia, as gerações seguintes entenderam que esse dilatado mapa era inútil e não sem impiedade o entregaram às inclemências do sol e dos invernos. Nos desertos do Oeste perduram despedaçadas ruínas do mapa, habitadas por animais e por mendigos; em todo o País não há outra relíquia das Disciplinas Geográficas. (Suárez Miranda: Viaje de Varones Prudentes, livro quarto, cap. XLV, Lérida, 1658). (BORGES, 1999, p. 247)

O perigo não está apenas na sedução gerada pelos mapas. 0 perigo está também na produção dos mapas. Na ação em si e na

\footnotetext{
${ }^{3}$ Em 1946, Borges era diretor de uma revista argentina chamada "Los Anales de Buenos Aires", onde escrevia, sob a rubrica de pseudônimos como H. Gering, B. Lynch Davis, Julio Platero Haedo ou, como no exemplo acima, Suárez Miranda. O texto em questão, que faz as vezes de uma citação, apareceu na seção "Museo" da supracitada revista, ano 1, n. 3, março de 1946, p. 53. Posteriormente, em 1960, o texto foi publicado novamente como parte do livro El Hacedor, capítulo Museo.
} 
posterior desconsideração de que aquele mapa é fruto do trabalho de um indivíduo, o cartógrafo. Os mapas são perigosos porque normalmente negligenciamos uma característica essencial de todos eles: eles não funcionam, e nunca funcionaram. Qualquer livro de cartografia justifica nos seus primeiros parágrafos que a Terra é esférica, mas o papel é plano, e todos sabemos, é impossível fazer uma folha de papel envolver uma esfera sem uma mínima dificuldade, tornando impossível a ação de desenhar um mapa verdadeiro da Terra em uma folha de papel. Os mapas não são cópias, são projeções. Aí os problemas começam: as projeções não são neutras, naturais ou dadas: elas são construídas, configuradas, apoiadas por várias e arbitrárias convenções.

Enquanto elabora um mapa, o cartógrafo deve escolher entre os modos de projeção azimutal, gnomônica, estereográfica, ortográfica, globular, cônica, cilíndrica, sinusoidal, cada qual carregando consigo muitos benefícios, mas também desvantagens. Em algum momento ou em alguma parte existirá uma necessidade de redução, distorção, omissão de alguma informação. Dá-se o início da ruína da verdade objetiva dos mapas, o momento em que o cartógrafo, sujeito, é convocado a manipular os dados do objeto. E sabemos que do sujeito é impossível esperar uma imparcialidade, uma isenção plena.

O cartógrafo tem perante si duas, ou mais, opções a escolher. Cabe a ele o poder da escolha, da eleição do que será considerado antes das outras coisas, o que terá preferência sobre as demais: onde a verdade, a representação fiel será considerada em sua totalidade e, consequentemente, onde a mesma verdade, a mesma representação fiel deverá ser simplificada, diminuída, reduzida, omitida.

Ou seja, o que vemos ao olharmos para um mapa, não é a realidade miniaturizada, e sim uma seleção cuidadosa e interessada de partes da realidade. Uma seleção que, se levada a um extremo, se 
torna fútil, e se levada a outro extremo, se estabelece uma crise de referenciais e uma anulação crítica ou completa inversão.

A cidade real, total e universal não jaz na racionalidade da luz, ar, geometria, circulação e transparências urbanas modernas, mas no fundo de seus quartos inacessíveis e câmaras trancadas, de seus porões escuros e sótãos claros, seus subterrâneos, intestinos, fendas e fissuras esquecidas e inatingíveis. O exercício cartográfico de descrição técnica, você finalmente concluirá, terá sido sempre fútil. (PEDROSA, 2005, p. 118)

Quem vem antes, o território ou o mapa? Hoje a abstração já não é a do mapa, do duplo, do espelho ou do conceito. (...) O território já não precede o mapa, nem Ihe sobrevive. É agora o mapa que precede o território - precessão dos simulacros - é ele que engendra 0 território cujos fragmentos apodrecem lentamente sobre a extensão do mapa. É o real e não o mapa, cujos vestígios subsistem aqui e ali, nos desertos que já não são os do Império, mas o nosso. O deserto do próprio real. (BAUDRILLARD, 1991, p.8)

Entre a futilidade e a crise, a utopia e a ruína, os artistas a seguir preferem enveredar por uma terceira via que não se apresenta facilmente. A via da inutilidade e da ficção. Caminho caminhado pelo Trapeiro. Caminho transformado em mapa inútil. Mapa que se desprende de todas aquelas "periculosidades" enumeradas acima. Mapas que

(...) inventam outras possibilidades narrativas, outras formas de compartilhar experiências. (...) [elas] são narrativas menores, são micronarrativas diante das grandes narrativas modernas; elas enfatizam as questões da experiência, do corpo e da alteridade. (JACQUES, 2012, p. 20)

Uma postura Trapeira que estabelece um outro território para os mapas. Território que

surge no reino da ficção e do fragmentário, do pessoal e do psicológico. Aí reside a força que conduz o pensamento e a prática da "Escola argentina de Cartografia". (...) Se Jorge Luis Borges viria a ser o pai filosófico, teórico e literário desta escola, hoje nos encontramos com dois cartógrafos pioneiros: Guillermo Kuitca e Jorge Macchi. (Adriano Pedrosa In MACCHI, 2011, p. 66) 
Cartógrafos que, como veremos, não concentram seus esforços na leitura unidimensional do espaço, e sim na leitura do espaço atravessado pelo corpo, pela experiência, pelo tempo.

\section{Guillermo Kuitca}

Guillermo David Kuitca ${ }^{4}$ nasceu no dia 22 de janeiro de 1961, na cidade de Buenos Aires, capital da Argentina. Seus pais, Jaime Kuitca, um contador, e Maria Kuperman, uma psicanalista infantil, eram filhos de imigrantes judeus vindos da atual Ucrânia durante a grande onda migratória europeia em direção à América do Sul no início do século XX.

Durante a ditadura militar argentina ${ }^{5}$, Kuitca se aproxima de cidadãos comuns, mas intelectuais e apreciadores de música, cinema, arte e arquitetura (Os pais de duas grandes amigas de juventude eram arquitetos). Nesse período, enquanto frequentava sessões de cinema e apresentações teatrais e musicais, se encantara por Pina Bausch e seu "Café Müller", em cartaz na cidade em 1979. Essa paixão platônica pela força estética e conceitual da obra da coreógrafa alemã, principalmente os jogos de cena desarmônicos entre corpos e cadeiras, marcará boa parte da produção artística posterior de Kuitca.

Em 1980, já pintando em atelier próprio, ingressa no curso de História da Arte na Facultad de Filosofía y Letras, da Universidad de Buenos Aires, mas abandona a formação, indefinidamente, ainda durante o primeiro ano. Simultaneamente expõe 80 obras na recém-inaugurada Fundación San Telmo, por conta de sua amizade com Daniel Helft, filho do casal de colecionadores donos da galeria.

Além disso, por conta da venda de alguns quadros na Fundación, viaja à Europa para uma experiência artística "imersiva" em Wuppertal, Alemanha, na sede da companhia Pina Bausch

\footnotetext{
${ }^{4}$ Todos os dados biográficos são referentes à documentação da curadora argentina e amiga do artista Sonia Becce, presentes na cronologia apresentada no livro-catálogo "Filosofia para princesas", organizado por Giancarlo Hannud (2014). 
Tanztheater. Segundo Kuitca "A companhia era formada por bailarinos que haviam renunciado à dança e eu me sentia um pintor que renunciara à pintura" (HANNUD, 2014, p. 198). De volta à Buenos Aires e a seu atelier, e por conta de sua paixão por Pina e a "dança teatralizada", iniciou e produziu vários projetos de direção e cenografia de peças teatrais.

Em 1982, enfrentando uma crise artística, quando ficava dias em seu atelier pintando esporadicamente, Kuitca inicia sua relação pictórica e simbólica com a "cama", um objeto vinculado à "ideia de território, como espaço físico que se habita, como plano no sentido arquitetônico do termo" (Kuitca In HANNUD, 2014, p. 199). Na série de pinturas que fez nas portas de um armário quebrado de seu atelier, intitulada "Nadie olvida nada" [Ninguém esquece nada], a cama desarrumada é o centro gravitacional e simbólico de obras que apresentam ao espectador a solidão, a ausência, o tempo perdido e que passou.

\footnotetext{
A cama de Kuitca é como a cadeira de Van Gogh: não uma cama particular (essa cama), mas sim A cama, um elemento icônico que é ao mesmo tempo abstrato e literal (é só uma cama, um território em escala corporal, e não necessariamente um teatro de desejo ou de morte). (Alan Pauls In HANNUD, 2014, p. 145)
}

Por conta de sua reconhecida qualidade pictórica e simbólica, Kuitca expõe, a partir de 1985, em diversos museus, galerias e mostras internacionais (Bélgica, Holanda, Estados Unidos, Brasil...), se tornando o representante do grupo de artistas da chamada Nova Pintura argentina. Kuitca passa a apropriar-se da estrutura musical e das representações gráficas da arquitetura e da cartografia em elementos e temas de seus quadros.

Para participar da XXa Bienal de São Paulo de 1989, pintou, sobre três colchões velhos, mapas de cidades, estradas e redes rodoviárias referenciando-se em um velho guia turístico de Praga e guias de viagem do interior da Europa. Para o artista, “o colchão e o mapa estavam relacionados de algum modo, por meio de uma 
conexão espacial que passava por cidades, casas, dormitórios e móveis" (In HANNUD, 2014, p. 202), numa plástica mudança de planos, num movimento de zoom-in e zoom-out, num convite ao espectador a ir e vir para "dentro" e para "fora" de seus quadros, visual e simbolicamente.

Já expondo, no início dos anos 1990, em diversos lugares do mundo, Kuitca sentia-se distante do meio artístico-urbano de Buenos Aires, mesmo morando e pintando na cidade. Por conta disso propôs um programa de bolsa de estudos para jovens pintores em seu estúdio, sob sua direção e orientação, com duração de dois anos. Sempre obteve patrocínios e apoio financeiro/administrativo de fundações nacionais e internacionais e uma considerável procura nos editas de seleção das vagas à bolsistas, as chamadas "Beca Kuitca". E, mesmo não tendo nenhum tipo de formação artística formal, foi sempre muito respeitado e elogiado pela sua sensível e didática postura perante os bolsistas, característica que o levou, em 2004, a receber o título de professor honorário da Universidad de Buenos Aires.

As obras de Kuitca têm sido amplamente estudadas e sempre recebem boas críticas por onde são expostas. Tais trabalhos se caracterizam por uma

\footnotetext{
[linguagem visual que] expressa uma vertiginosa visão de mundo, um sentido de perda, de anonimato e de isolamento urbano, formando um estranho tecido de contradições e dissonâncias. (...) [e] sugerem uma suposta inversão de audiências, como observamos na série de cartografias e plantas arquitetônicas, onde nenhum personagem habita o plano representacional da tela, ativado apenas pela presença do espectador. (Vanda Klabin In KUITCA, 1999, p. 04)
}

Com uma vasta, complexa e profunda produção artística, se valendo de relações simbólicas com elementos arquitetônicos e urbanos, como plantas de apartamentos genéricas, esquemas espaciais de disposição das poltronas em platéias de teatros, 
representações técnicas de projetos de escolas, prisões, hospitais, igrejas, Kuitca se vale da constatação de que

levar à pintura qualquer projeto relacionado com esse espírito de catalogação [em que o mundo parece estar completamente organizado, medido, calculado, representado pelo "Neufert"] se torna totalmente absurdo. A pintura produz enorme arbitrariedade referencial, enquanto a arquitetura faz justamente o contrário." (Kuitca In HANNUD, 2014, p. 207)

Mas em meio a toda essa interessante produção, uma obra se destaca e se apresenta como possível maneira e expressão de um Trapeiro contemporâneo e, por isso, será aqui inventariada e adicionada na coleção de exemplos de apropriação e incorporação da figura do trapeiro.

A obra em questão é, na verdade, um conjunto de colchões com mapas pintados, inicialmente (em 1988) composto por três elementos pensados e apresentados como peças independentes e sem título. O conjunto irá crescer e se configurar como uma série em 1992, ainda sem título, e composta por 50 elementos. É apenas em 2010 que a série é batizada oficialmente de "Le Sacre" (1992) [A Sagração, 1992], composta agora por 74 elementos, que se encontram divididos em duas coleções distintas: 54 delas fazem parte do acervo do Museum of Fine Arts, Houston e as outras 20 se encontram na Tate Gallery em Londres. Ao batizar o conjunto, Kuitca lembra que

as obras mapas-em-colchões representam um ponto de encontro de experiências de público e privado. No entanto, agora também percebo essa grande plataforma de camas como a superfície onde um "rito" ou uma "sagração" ocorre.

LE SACRE (1992) é oficialmente apresentada como um “mapa pintado com acrílica sobre colchão e pés de madeira e bronze, 54/20

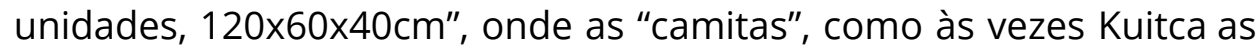
menciona, são apresentadas como uma instalação e dispostas de diversas formas: alinhadas, compactas, dispersas, quase sempre no 
chão dos espaços expositivos, mas também podendo aparecer fixadas na parede do museu (como exibida no MALBA, Buenos Aires em 2003) ou nas paredes de um elevador de carga (na Sperone Westwater Gallery de Nova York em 2010).

Surgiu na minha cabeça a imagem de um louco preso num recinto com paredes acolchoadas quando comecei a trabalhar nas pinturas sobre colchões. Embora a cama já fosse um leitmotiv há muito tempo nos meus quadros, acho que eu estava fascinado por superfícies semelhantes a um colchão com botões, usados antigamente para evitar que pessoas enfurecidas batessem com a cabeça na parede. (KUITCA, 1999, p. 32)

As camas-mapas de Kuitca são pequenas (camas de crianças?), parecem carbonizadas ou embebidas em um pigmento cinza (são usadas e abandonadas?), trazem mapas rodoviários de diversas regiões da Terra, como Birmingham, Medelín, Maastricht, Kabul. As estampas e texturas originais dos colchões (flores, barcos, rendas, listras) se misturam com as representações e símbolos dos mapas, os nomes das cidades e as linhas vermelhas, verdes e pretas das rodovias e caminhos. Alguns botões, típicos de estofamentos capitonê, aparecem dispostos irregularmente na superfície do colchão e fazem as vezes das indicações das "grandes" cidades.

Le Sacre obviamente é um desenvolvimento do meu trabalho com colchões, retomando a primeira obra que fiz com esse objeto, uma série de três colchões que foi mostrada na Bienal de São Paulo de 1989. As camas de Le Sacre são menores do que camas de verdade, por isso às vezes são chamadas de "camitas". É importante dizer que não são camas de criança. A minha ideia não é que as camas sejam pequenas, mas sim que sejam vistas de longe. Eu queria brincar com a perspectiva e o tamanho das coisas; não estamos tão próximos delas quanto pensamos. Eu queria um olhar ampliado de algo, como a cama, um objeto tão próximo quanto nosso próprio corpo, para então visualizá-la dentro da casa, a casa dentro da cidade, e a cidade dentro do mapa. Um zoom que se aproxima cada vez mais, ou se afasta cada vez mais. (Kuitca In HANNUD, 2014, p. 35)

O trapeiro Kuitca, que não recolhe concretamente nenhum trapo, mas sim sugere e imagina a ação, anuncia e provoca o 
espectador a "aprender algo a respeito de si próprio" (KUITCA, 1999, p. 44), a resgatar de um limbo temporal trapos de histórias contadas e esquecidas, rastros de algo que foi ocupado pelo corpo, espaços de ausência e de solidão, presenças e memórias submergidas, distantes ou mortas.

As camas-mapas, planos de uma sagração, nos convidam ao devaneio, à divagação onírica, a explorar um estado "nômade" (proposta de Deleuze e Guattari quando indicam um corpo subordinado aos caminhos e não aos pontos iniciais e finais), a desenhar uma rota imaginária, a viajar.

Mas os mapas são superfícies em que se expõem montagens do mundo, trechos de mundos descritos. Descrições que Kuitca adultera e inutiliza com mudanças de nomes e rotas do mapa referencial, algumas vezes repetindo o nome de uma cidade em pontos distintos (repetindo a ideia de Borges de que um lugar é todos os lugares, um dia é todos os dias); “o mapa com o nome da mesma cidade repetido foi uma espécie de visão. Vejo uma pessoa saindo de um lugar e chegando ao mesmo lugar." (KUITCA, 1999, p. 33).

Como são sempre fragmentos de uma entidade maior e não têm começo nem fim, nem coordenada nem origem, elas [as camas-mapas] também terminam propondo um estado de suspensão. (Lynne Cooke In KUITCA, 1999, p. 41)

Estado de suspensão, as camas-mapas

(...) podem ser lidas como ruínas ou fragmentos do mapa perfeito de Borges [citado no início deste fragmento]: os mapas sobre colchões ressaltam o micro e o macro, o pessoal e o relativo ao corpo com o imperial e o geográfico. Neste caso, o corpo, sempre ausente na cartografia tradicional, é recuperado metonimicamente mediante seu mais íntimo receptáculo: a cama (como uma ruína). (Adriano Pedrosa In MACCHI, 2011, p. 66)

“Nestas superfícies, o privado e o público se condensam, se fundem. A cama contém os atos mais privados dos homens; os mapas, informações anônimas e acessíveis" (Sonia Becce In KUITCA, 
1999, p. 17). Ao depararmo-nos com esses objetos, camas e mapas, que nos fazem cambalear entre a privacidade, o íntimo, a presença iminente do corpo, o reconhecimento pessoal individualizado que reconhecemos na "cama", e a "publicidade", o compartilhado, a ausência objetiva do corpo, o anonimato impessoal e generalizante que encontramos no "mapa", estamos perante uma proposta feita por Kuitca, o Trapeiro: é preciso resgatar esses fragmentos de vida, esses momentos abandonados em plena rua, nossos rastros deixados pela nossa passagem; resgatá-los e aproximá-los de nosso corpo, mantê-los em nós, sobre nós. Habitá-los.

\begin{abstract}
Independentemente de qualquer valor ontológico que porventura lhe atribuamos, a cama é o lugar do sono, do amor, do nascimento e da morte. Este objeto cotidiano, porém, não está longe de uma outra dimensão. Ele pode também ser vivenciado como um diagrama que precede experiências possíveis, espaço virtual cuja pura presença prenuncia eventos ainda não ocorridos; em outras palavras, a cama pintada pode também ser um plano: o desenho fundamental de parte de uma topologia destinada à habitação. Neste sentido, a cama torna-se o plano - no sentido de "projeto" e no de "superfície" - que habitamos. (KUITCA, 1999, p. 55)
\end{abstract}

\title{
4. Jorge Macchi
}

Nascido em Buenos Aires no ano de 1963, o argentino Jorge Macchi é artista formado na Escuela Nacional de Bellas Artes de Buenos Aires (1983-1987), obtendo o título de Professor Nacional de Pintura em 1987. No início de sua carreira, integrou o coletivo de jovens pintores argentinos El Grupo de la X, responsáveis por apontar uma crise ao neoexpressionismo tão em evidência na Argentina, e por revalidar o conceitualismo na arte, "encabeçada" por Duchamp nos anos 1920-30.

Praticamente durante todos os anos da década de 1990 Macchi foi um "artista em trânsito". Em 1993 recebe uma bolsa de artista residente da Cité des Arts, indo morar em Paris durante 2 anos. Já em 1996, é artista residente em Rotterdam, na Holanda, por conta do programa Duende Artists. Dali parte, no ano seguinte, em 
direção à Londres por conta da bolsa Delfino Studio. Em 1998 passa uma curta temporada como artista residente na universidade de Plüschow, na Alemanha, regressando à Buenos Aires no início de 1999.

Artista do mundo, um eterno estrangeiro, vai carregar consigo uma sensação de desterritorialidade e confusão cultural e urbana, transmitidas para suas obras de arte, agora já não apenas tendo a pintura como suporte e técnica, mas expandindo os procedimentos artísticos à escultura, fotografia, instalação, desenho, gravura, colagem, vídeo.

O período de residência em Londres foi crucial para a configuração expandida e mais "conceitual" (mesmo Macchi sendo bastante avesso à tais categorizações artísticas) da produção do artista argentino. Lá, Macchi se dedica a uma observação curiosa aos objetos, às coisas do cotidiano. O artista volta-se ao potencial absurdo da vida cotidiana, onde encontra, em travesseiros (Pentagrama e Untitled, ambos de 1993), degraus de escadarias (Escalón, 1995), sombras de janelas (Accident in Rotterdam, 1996), cabelos e molduras (A.B., 1996), notícias sensacionalistas (Incidental Music, 1997), vidros quebrados e caixas de fósforos (Vidas paralelas, 1998), motivos para estabelecer e construir significado e complexidade para uma nova relação com a vida.

O ponto importante aqui é o de que não existe uma explicação única que possa exaurir as possibilidades contidas no objeto, assim como não existe um texto que possa substituir a experiência de encontrar o objeto. (PÉREZ-BARREIRO, 2007, p. 31)

A escolha de Macchi por objetos cotidianos é significativa. Por meio das operações mais simples, esses objetos passam por um processo de desfamiliarização a ponto do óbvio tornar-se extraordinário. (PÉREZ-BARREIRO, 2007, p. 31-2)

Essa capacidade de encontrar o significativo no cotidiano tem pouco relação com uma linguagem formal e tudo a ver com o refinamento de uma sensibilidade e um olhar para o extraordinário inserido no comum. (PÉREZ-BARREIRO, 2007, p. 35) 
Ao regressar dessa longa e produtiva estadia no exterior, Macchi se reencontra com sua cidade natal, sentindo-se um estranho, desconhecido e desconhecendo seu próprio ambiente. O artista, então, foi à cidade, como um legítimo Trapeiro Contemporâneo, para retomar o que era seu e reinserir-se onde imaginava pertencer. Recolheu trapos do que supôs ser uma cidade e uma vida naquela Buenos Aires que apontava um futuro incerto e economicamente problemático. O artista, desfamiliarizado, começou a buscar nos fragmentos que encontrava pela cidade, uma maneira de resgatar as próprias memórias, ressignificando tais "objetos" cotidianos encontrados.

Aqui temos um deslocamento do Macchi produtor de objetos ansiosos para o Macchi visionário de um mundo misterioso que encontra-se logo abaixo da superfície da banalidade. (PÉREZ-BARREIRO, 2007, p. 35)

Mais do que apenas um artista construindo novas relações simbólicas com os objetos, Macchi se vê como "um produtor de ficção" (MACCHI, 2011, p. 140), um colecionador de banalidades cotidianas constituindo narrativas a partir de objetos. Narrativas fictícias baseadas numa realidade crua e cotidiana... Cotidianidade; "onde tudo <parece> dramaticamente ordenado como em uma coreografia”, como percebe Rudnitzky, "onde tudo é perfeito até que o coreógrafo ou algum dos bailarinos se distraia e... zaz!" (MACCHI, 2011, p. 155)

Ordenação e harmonia humanas e urbanas frágeis, superficiais, onde Macchi faz-se valer deste “...zaz!”, tomando para si a oportunidade de ser esse “...zaz!", experimentando, num sadismo criativo e revelador, a violência gerada com a instabilidade de uma "ressignificação trapeira": durante semanas de 2000, Macchi perambula pelas ruas de Buenos Aires registrando, em tomadas de vídeo e fotografias, palavras e fragmentos de palavras de anúncios publicitários, placas comerciais, sinalizações urbanas, cartazes e 
panfletos distribuídos de mão em mão ou colados em muros e postes. "Descoladas" de seus contextos e depois remontadas seguindo uma outra lógica, as palavras se transformam em uma espécie de aviso endereçado ao transeunte atento e paranóico: a VÍCTIMA SERIAL (2001). Obra desmembrada em dois suportes distintos: um deles como uma colagem sequencial composta por 60 fotos 10x15, "avisando": <<Te llegó la hora. Tú última chance se hace polvo. Me rio de vos. Sabés que no tenés salida. Tu casa no es más un alivio. No tenés a donde ir. Lo único que te espera es la muerte. Te voy a perseguir hasta dejarte sin aire. Te voy a hacer carne picada. Ya no me basta solamente con verte sufrir $>>>^{6}$. O outro suporte é o de uma projeção de vídeo em looping com duração de um minuto e quarenta segundos apresentando as frases compostas pelas palavras resgatadas, seguido de uma pausa silenciosa e vazia de 10 segundos de uma tela preta, retomando, na sequencia, os mesmos $01 \mathrm{~min} 40 \mathrm{~s}$ anteriores. O "aviso" dado no vídeo é: $<<<$ Rabia. Eso es lo único que siento. Rabia sin límites. Como un hierro caliente en el centro de mi corazón. Pero ya van a ver. No se van a olvidar de mi rabia jamás. Está todo listo. Los voy a hacer puré. De nada vale prevenirse. No hay lugar a donde ir. Yo voy a estar en todos lados. Necesito sangre. Mucha sangre. La sangre me va a hacer olvidar para siempre la sombra permanente que siento sobre mí. Todavía hay mucho por hacer. Ya fueron dos las victimas y hay más. Ahora viene lo mejor._____ >> $>>$.

Outra forma de explorar o cotidiano e resignificar objetos e signos é estabelecido pelo artista-trapeiro através de especulações e manipulações de mapas urbanos. Próximas de uma obsessão formal, as obras de mapas recortados por Macchi retomam as noções de "fantasma" e de "estranhamente familiar" de Freud. O artista se

\footnotetext{
${ }^{6}$ Em uma tradução livre: <<<Chegou sua hora. Sua última chance virou pó. Gargalho de você. Você sabe que não tem saída. Tua casa já não é mais um refúgio. Não tens mais para onde ir. A única coisa que te espera é a morte. Vou te perseguir até te deixar sem ar. Vou fazer de você picadinho. Não me satisfaço mais em apenas ver você sofrer.>>>

${ }^{7}$ Em uma tradução livre: $<<<$ Raiva. É a única coisa que sinto. Raiva sem limites. Como um punhal em chamas enfiado no centro do meu coração. Mas todos verão. Não se esquecerão da minha raiva jamais. Está tudo preparado. Vou fazer deles purê. Não adianta prevenir-se. Não há para onde ir. Estarei por todos os lados. Preciso de sangue. Muito sangue. O sangue me fará esquecer para sempre da sombra permanente que sinto sobre mim. Mas há muito o que fazer. Já são duas vítimas e serão mais. Agora vem a melhor parte. $>>$.
} 
apropria desses objetos tão conhecidos como instrumento útil de familiarização e orientação no território e os rompe de quaisquer referenciais. Retirada da "terra firme". Retirada da objetiva (mas falsa e parcial) reprodução da realidade. Retirada da utilidade.

Existe nestas obras, inclusive, uma questão de materialidade. $\mathrm{Na}$ medida em que se tornam mapas vazios, o papel perde sentido como suporte mas cobra sentido como material. Uma materialidade que se cai e que perde rigidez finalmente se transforma em uma folha morta. ${ }^{8}$

Os mapas de cidades vão perdendo seus quarteirões nas mãos pacientes e precisas de Macchi, mas, em contrapartida, vão ganhando espaços, vazios, lacunas, outras possibilidades de significados, interações, relações; não mais aquelas estritamente funcionais de seus momentos anteriores. As cidades-mapas perdem seus locais de origem e destino, ficam apenas com os caminhos, os espaços entre, os meios. O que era figura, agora é ausência; o que era fundo agora é a única presença. Ao abrir espaços nas cidades-mapas, abre-se caminhos para outras significações, outras narrativas, outras relações com o "objeto".

As cidades-mapas ganham, perante o olhar interessado de Macchi, lacunas preenchidas por adjetivos "animados": quieta, perfeita, maldita, imóvel, cansada. Mas já foi dito em algum lugar que "(...) as cidades não sentem; o homem sente", em outras palavras, tais adjetivos "dados" às cidades-mapas, como preenchimento das lacunas recentes, são na verdade do próprio observador.

Jorge Macchi se apropriou (poderíamos dizer até "incorporou") de várias cidades-mapas, jogando regras específicas com cada uma delas. 32 MORCEAUX D'EAU (1994) [32 pedaços d'água] são os pedaços do rio Sena fracionado pelas pontes da cidade de Paris, recortados do mapa e reaproximados em uma colagem sobre cartão. Além disso, cada um dos pedaços ganha valor

${ }^{8}$ Jorge Macchi responde a pergunta de Alejandra Aguado, em entrevista para a revista italiana FlashArt n. 277, edição de mar-abr de 2011. 
individual, não mais como mera parte do rio, mas como "pedaço" do Sena, em reproduções ampliadas de suas formas em guache azul. AMSTERDAM (2002) apresenta o mapa dessa cidade composto apenas pelos canais que cruzam o espaço urbano. GUíA DE INMOVILIDAD (2003) é um guia das ruas de Buenos Aires no qual todos os quarteirões foram recortados, ficando apenas uma sobreposição de páginas e mais páginas de caminhos. O mesmo é feito com São Paulo - MAPA DE LAS ARTES (2003) e LA CIUDAD QUIETA (2003), La Plata - LA CIUDAD PERFECTA (2003), Veneza VENECIA (2004), Cidade do México - CIUDAD CANSADA (2004), Buenos Aires - SLEEPING CITY (2004), Lisboa - LA CIUDAD SILENCIOSA (2004) e AUTUMN IN LISBON (2004), um mapa da cidade no qual restam apenas os cemitérios, e Roma - LA MALEDIZIONE (2003), onde o rio Tibre aparece recortado de seu leito original e realocado a alguns quilômetros a leste no tecido urbano histórico.

Mas a experiência máxima de Jorge Macchi, pelo menos quando considerado aqui a intenção de perceber, destacar e inventariar as experiências artísticas do Trapeiro Contemporâneo, talvez seja a obra ação-instalação-livro BUENOS AIRES TOUR (2003).

Trabalho produzido entre 2000 e $2001^{9}$, em conjunto com a escritora argentina residente em Nova York, Mariá Negroni, e do musicista argentino residente em Berlim, Edgardo Rudnitzky. A obra foi apresentada inicialmente como uma instalação exposta na $8^{\text {a }}$ Bienal de Istambul e na Galería Distrito 4, em Madri, ambas em $2003^{10}$

A obra consiste em produzir um procedimento alternativo de leitura e apropriação da cidade, diferente dos roteiros e dicas pasteurizados e homogeneizantes propostos e proporcionados pelos tradicionais guias turísticos (aqui vê-se uma clara referência às

\footnotetext{
${ }^{9}$ Graças à bolsa recebida por Jorge Macchi da Fundação John Simon Guggenheim Memorial de Nova York e do Fundo Nacional de las Artes de Buenos Aires.

10 Hoje a instalação e todos os materiais originais fazem parte da coleção do Museu de Arte Contemporânea de Castilla y León, na Espanha.
} 
propostas de visitas realizadas pelo grupo Dada na Paris de 1921). Macchi propõe um procedimento metodológico mais errático, definido pelo acaso e pelo acidental: guiar-se pela cidade seguindo uma trama produzida pelas rachaduras de um vidro quebrado sobre o mapa da cidade.

Macchi, na companhia de seus dois amigos, coloca um painel de vidro transparente sobre um mapa de Buenos Aires e o alveja com um martelo, gerando uma série de rachaduras ${ }^{11}$. O ponto de impacto (esquina das ruas México e Santiago del Estero, endereço do atelier do artista) e a ação que gerou a quebra foram os únicos elementos controlados pelo artista, todo o restante do trabalho ficou a cargo do acaso. Com as rachaduras do vidro sobre o mapa, os três artistas constatam a existência de 8 linhas/vetores cruzando a região central da cidade, passando por locais bastante familiares: a Avenida 9 de Julio, a Plaza de Mayo, o bairro e o cemitério da Recoleta, a Boca.

Sobrepondo estas oito linhas (que ganharam cores e números, numa simbólica referência ao mapa de metrô de Londres: 1-laranja, 2-preto, 3-azul, 4-marrom, 5-ciano, 6-vermelho, 7-verde e 8-violeta) com a trama de ruas e avenidas do mapa base, foram marcados 46 pontos de interesses (esquinas e cruzamento, por exemplo San Jose y Av. de Mayo, na linha vermelha). O passo seguinte foi percorrer, sozinhos ou com o grupo, durante vários dias e horários, os 46 pontos marcados e registrar em texto, foto e gravação de áudio qualquer coisa que lhes chamasse a atenção naqueles locais, naqueles momentos. Além disso, vários objetos (objets trouvés) foram encontrados e recolhidos, sendo também registrados (cartas de baralho espanhol, panfletos de ofertas, uma boneca quebrada, bitucas de cigarro, um gato morto, uma lista de compras de supermercado, próteses, imagens religiosas, peças de quebra-cabeça).

\footnotetext{
1 O aspecto da rachadura produzida pode ser entendido como o sistema de orientação organizador do mapa que virá a seguir, assim como nos mapas tradicionais existe a indicação fundamental das coordenadas e do norte, representados pela "estrela dos ventos". Talvez por coincidência o verbo em espanhol "estrellarse", colidir violentamente contra algo, venha a fazer tanto sentido na proposta.
} 
Ao contrário das cidades-mapas recortadas, onde tentava-se transformar as cidades em simples tramas, estruturas ósseas sem carne e nuas, em Buenos Aires Tour Macchi e seus colegas pretendiam ver além da trama da cidade e perceber seus elementos intersticiais.

Além da ação propriamente dita (que já nos serviria de apropriação metodológica do Trapeiro Contemporâneo), Jorge Macchi organizou todo o material e o publicou como um guia turístico real. $\mathrm{O}$ guia, publicado pela editora Turner Libros, de Madri, como uma caixa-livro de 21,5 x 15,5 x 06 cm, numa tiragem de 1000 exemplares não numerados e 100 exemplares numerados e assinados, e que contém 10 itens: um guia com 170 páginas contendo fotos feitas por Macchi dos locais e dos objetos encontrados e poemas em prosa escritos por Negroni em cada um dos 46 pontos; um mapa dobrado mostrando os oito itinerários e seus respectivos pontos; um CD-ROM contendo todas as gravações de áudio in-loco feitas por Edgardo e um guia virtual para outras possíveis navegações pelas linhas; um fac-símile em tamanho real de um caderno de estudos de inglês manuscritos com 127 páginas, encontrado na calçada e de propriedade de um tal Sr. Luis M.; um fac-simile de um missal encontrado na rua (reprodução de La Santa Misa segundo las novísimas y definitivas disposiciones de la Santa Sede. Celebración de la Palabra para los velatorios. Buenos Aires: Editora Guadalupe, 1969, 12p.); um fac-símile de uma carta manuscrita encontrada em um envelope, contendo palavras de despedida de um suicida; um envelope com 8 postais sanfonados, de fotos de sombras de cruzes do cemitério Recoleta; 4 postais avulsos de capas de revistas encontradas; uma cartela com 9 selos destacáveis estampados com a reprodução de uma capa de livro encontrada em um dos pontos; um encarte de 39 páginas com a versão em inglês dos textos de Negroni.

O kit vem acompanhado de um pequeno folheto apresentando o guia: 
Este guia brinda os visitantes que têm apenas poucos dias para passear por Buenos Aires, mas também aos que nela habitam, com a possibilidade de se aprofundar no conhecimento desta cidade.

Buenos Aires Tour consta de 8 itinerários que reproduzem a trama de linhas de um vidro quebrado sobre o mapa da cidade de Buenos Aires. Ao longo das 8 linhas foram escolhidos 46 pontos de interesse, sobre os quais o guia proporciona informação escrita, fotográfica e sonora. Com a ajuda do mapa e do CD-ROM o leitor poderá estabelecer seu próprio itinerário, além dos propostos pelo guia. (MACCHI; NEGRONI; RUDNITZKY, 2004, p. 3)

Os artistas estruturam todo o guia com base nas dimensões do caderno de estudos de inglês encontrado no ponto Riachuelo da linha 1-Laranja, onde encontra-se anotado uma grande lista de termos em inglês com suas respectivas traduções para o espanhol (muitas delas equivocadas e com erros de interpretação da língua inglesa), numa espécie de dicionário inglês-espanhol personalizado.

\begin{abstract}
O guia turístico se baseia na crença de que se você for de ponto a ponto para ver quais são os lugares considerados mais importantes na cidade, você irá conhecer a cidade. Da mesma forma, o dicionário é baseado na premissa de que se se conhece as traduções palavra por palavra, conhece-se a língua. (Macchi In JAGOE, 2007, p. 53)
\end{abstract}

Ou seja, Jorge Macchi está o tempo todo deixando-se levar pelo acaso e pelas referências externas ao trabalho para direcionar seus itinerários pela cidade e suas formas de coleta, organização e catalogação dos materiais encontrados durante as caminhadas, sejam eles objetos, fotos, sons ou impressões e memórias. A diretriz sempre está na valorização e ressignificação das banalidades insignificantes do cotidiano, inclusive informações e memórias prévias que temos dos locais (re)visitados.

Buenos Aires Tour é um livro. Um livro que tem o aspecto de um guia de turismo. Mas, diferente destes guias, com seus itinerários por edifícios e lugares importantes de uma cidade, meu livro estabelece uma rota determinada pelo acaso, onde os lugares, os edifícios e os objetos são insignificantes e até sua existência é provisória. (Macchi In JAGOE, 2007, p. 55) 
A ideia de algo provisório é fundamental na compreensão deste procedimento e das relações com os espaços urbanos da vida cotidiana, basta lembrarmo-nos da tentativa frustrada de esgotar documentalmente um local parisiense realizada por Georges Perec, ação inviabilizada pelo simples fato da ação impiedosa da passagem do tempo, da transitoriedade dos momentos. Como grande parte dos registros realizados pelos três artistas argentinos estão baseados em momentos passageiros, únicos, que certamente desapareceram instantes depois do registrar, as indicações "turísticas" do guia resultante se tornam imprecisas, equivocadas, inúteis. Tornam-se rastros na narrativa ficcional construída pelos artistas.

\footnotetext{
Tanto para a coleta do material como para a posterior elaboração do guia nos impusemos uma série de questões: não informar, não ilustrar, enfatizar o provisório. Assim o guia se torna um objeto absolutamente "inútil" e torna também inútil a realização do tour por parte de um eventual leitor. (Macchi In JAGOE, 2007, p. 55)
}

Narrativa ficcional que elogia a inutilidade perante a lógica da descrição superficial de um território empreendida pelos sistemas hegemônicos de leitura e intervenção nas cidades contemporâneas. Jorge Macchi está mais interessado, como sensato Trapeiro, na criação de sentidos alternativos, cambiantes, subjetivos para os rastros e trapos com os quais nos deparamos constantemente. Encontros constantes mas sempre incontroláveis, selvagens, indomáveis, dominados pelo mais puro acaso, que “(...) em alguns casos, traz como consequência situações agradáveis (...) por isso na ficção que estabeleço para meu trabalho eu posso controlar o acaso, congelá-lo, repeti-lo" (MACCHI, 2011, p. 151).

Jorge Macchi, com Buenos Aires Tour, anuncia a criação de uma "zona de penumbra" ${ }^{12}$, um espaço aberto e fértil na realidade urbana. Um espaço entre a forma real e a forma fictícia da realidade

\footnotetext{
${ }^{12}$ Termo proposto por Thibaut Verhoeven (MACCHI, 2011, p. 104). No original "Twilight Zone".
} 
que encontramos na cidade. Um espaço entre a negação da realidade racional imperativa e a confirmação de uma realidade subjetiva e pessoal. Um espaço entre a realidade racional interpretativa e uma realidade emocional perceptiva. Um gesto poderoso e sugestivo "precisamente porque se move constantemente entre o desejo de estressar cada momento como sendo único, e o fato de que isso só pode ser percebido se houver lembranças enraizadas, petrificadas que permitam a percepção do movimento" (JAGOE, 2007, p. 51)

(...) essa é a razão pela qual chamei dois portenhos para colaborar na obra, porque conheciam a cidade e porque tinham um passado nela. Se não fosse assim, talvez o trabalho teria se reduzido a uma questão mais turística, mais externa. Quando penso neste projeto o enxergo como um autorretrato em três partes: o mapa da cidade e a própria cidade deixam de ser o suporte de uns itinerários turísticos para transformarem-se em um espelho: um registro, que não é imparcial, de nossas histórias, de nossas impressões e de nossas decisões. ${ }^{13}$

Buenos Aires Tour evidencia a percepção urbana simplificada e parcial que se generaliza nos nossos tempos, sempre vinculada ao consumo, a espetacularização, ao fetiche pelas relações instantâneas, às apropriações dos espaços urbanos superficiais e simuladas. Mas, ao mesmo tempo, Macchi e sua obra oferecem uma alternativa a essa percepção, mais realista e sedutora. A proposta é a de incorporação do Trapeiro, a constituição de "narrativas fraturadas" (JAGOE, 2007), como o vidro sobre o mapa, que sejam determinadas em momentos no tempo, com uma criação de diálogo com o já conhecido da cidade, em um capturar, resgatar, colecionar relacionado com uma libertação da experiência do acaso, do inútil, do efêmero nos movimentos e relacionamentos com a cidade.

Parciais, improváveis e imprecisos, os mapas de Macchi não nos oferecem a ilusão de que o mundo possa ser perfeitamente reduzido ou dominado por uma representação abrangente, quer seja plana ou totalmente redonda. Os mapas de Macchi nos dizem que a realidade é muito complexa e fugaz para ser

13 Jorge Macchi explicando sua obra em conversa com Ana Paula Cohen, para o dossiê "em obras - 26a Bienal Internacional de São Paulo". Site da instituição. 
traduzida por completo mediante uma troca de escalas, de modo que só é possível entendê-la de forma incompleta e fragmentária. (Adriano Pedrosa In MACCHI, 2011, p. 72)

Por tudo isso Jorge Macchi é Trapeiro Contemporâneo, muito mais que o "Flâneur na cidade global do nosso tempo" sugerido por José Jiménez ${ }^{14}$. E por tudo aquilo já dito Buenos Aires Tour é um exemplo raro e profundo da incorporação e apropriação da cidade contemporânea realizada pelo Trapeiro. Rara e profunda, mas ao mesmo tempo agenciada a partir do ordinário, cotidiano, banal, com uma preocupação sensível ao tempo, à memória, às percepções possíveis.

Buenos Aires Tour [e Jorge Macchi] não se coloca como algo autoritário, e deixa claro que é uma narrativa entre muitas possíveis. Afinal de contas, o vidro fraturado é transparente, então as rachaduras-linhas são apenas mais uma trajetória que pode ser feita através do mapa da cidade. (JAGOE, 2007, p. 63)

${ }^{14}$ In JIMÉNEZZ, J. El final del eclipse: el arte de América Latina en la transición al sig/o XXI. 2002. 


\section{Referências}

BAUDELAIRE, Charles. O Pintor da Vida moderna. Belo Horizonte: Autêntica Editora, 2010.

BAUDRILLARD, Jean. Simulacros e simulação. Lisboa: Relógio D’água, 1991.

BORGES, Jorge Luis. Obras completas, vol. II (O fazedor). São Paulo: Globo, 1999.

GAUTIER, Théophile. Baudelaire. São Paulo: Boitempo, 2001.

GIEDION, Siegfrid. Espaço, tempo e arquitetura: o desenvolvimento de uma nova tradição. São Paulo: Martins Fontes, 2004.

HANNUD, Giancarlo (org). Guillermo Kuitca: filosofia para princesas. São Paulo: Pinacoteca do Estado, 2014.

JACQUES, Paola Berenstein. Elogio aos errantes. Salvador: EDUFBA, 2012.

JAGOE, Eva-Lynn Alicia. Jorge Macchi's Fractured Narratives of Buenos Aires. In ADES, Dawn. Light Music, catalogue. Colchester: University of Essex, 2007, p. 46-63.

KUITCA, Guillermo. Guillermo Kuitca. Rio de Janeiro: Centro de arte Hélio Oiticica, 1999.

MACCHI, Jorge. Music stands still. Barcelona: S.M.A.K./KBB, 2011.

MACCHI, Jorge; NEGRONI, Mariá; RUDNITZKY, Edgardo. Buenos Aires Tour. Madrid: Turner Libros, 2004.

PASSOS, Maria Lúcia Perrone. Desenhando São Paulo: mapas e literatura: 1877-1954. São Paulo: Editora Senac: Imprensa Oficial, 2009.

PEDROSA, Adriano (org.). Fragmentos e souvenirs paulistanos. Vol. 1. São Paulo: Galeria Luisa Strina, 2005.

PÉREZ-BARREIRO, Gabriel. Jorge Macchi: exposição monográfica. Porto Alegre: Fundação Bienal do Mercosul, 2007.

WILDE, Oscar. 0 retrato de Dorian Gray. São Paulo: Hedra, 2009.

\section{Resumo}

O presente artigo pretende encontrar quem fale do espaço urbano e de nossas experiências como seres humanos/urbanos. Encontrar quem tencione e especule propositivamente sobre o anestesiamento e silenciamento dos dissensos urbanos, sobre a homogeneização e estandardização da vida cotidiana, sobre o viver urbano, sobreviver urbano. Encontrar na Arte quem assuma o choque moderno (o ainda insistente ensaiado por Benjamin) e incorpore o 
DOI:10.20396/urbana.v11i3.8655998

turbilhão informacional contemporâneo e que nos convoque a um deslocamento necessário à reflexão e constituição da subjetividade, da alteridade, da urbanidade. Nessa busca, caminhar e encontrar alguns artistas contemporâneos, colecionar algumas de suas obras e estabelecer uma análise crítica. Os trabalhos artísticos centrais são: Le Sacre (1992), de Guillermo Kuitca e Buenos Aires Tour (2003), de Jorge Macchi.

Palavras-chave: Leituras Urbanas. Trapeiro. Alteridade Urbana.

\section{Abstract}

The present article intends to find who speaks of the urban space and of our experiences as human / urban beings. Finding who proposes and speculates propositively about the anesthetization and silencing of urban dissent, about the homogenization and standardization of everyday life, about urban living, urban survival. Finding in the Art who assumes the modern shock (the still insistent rehearsed by Benjamin) and incorporate the contemporary informational tourbillon and that calls us to a necessary displacement to the reflection and constitution of subjectivity, alterity, and urbanity. In this search, walk and meet some contemporary artists, collect some of his works and establish a critical analysis. The central works are: Le Sacre (1992), by Guillermo Kuitca and Buenos Aires Tour (2003), by Jorge Macchi. Keywords: Urban readings. Ragman.Urban Otherness.

\section{Resumen}

El presente artículo pretende descubrir quién habla del espacio urbano y de nuestras experiencias como seres humanos / urbanos. Averiguar quién propone y especula sobre la anestesia y el silenciamiento de la disidencia urbana, sobre la homogeneización y la estandarización de la vida cotidiana, sobre la vida urbana, la supervivencia urbana. Encontrar en Arte quién asume el shock moderno (el todavía insistente ensayado por Benjamin) e incorpora el torbellino informativo contemporáneo y que nos llama a un desplazamiento necesario para la reflexión y la constitución de la subjetividad, la alteridad y la urbanidad. En esta búsqueda, caminar y encontrar a algunos artistas contemporáneos, recopilar algunas de sus obras y establecer un análisis crítico. Las obras centrales son: Le Sacre (1992), de Guillermo Kuitca y Buenos Aires Tour (2003), de Jorge Macchi.

Palabras clave: Lectura Urbana. Trapero. Alteridad Urbana. 